\title{
Nodal Marginal Zone Lymphoma
}

National Cancer Institute

\section{Source}

National Cancer Institute. Nodal Marginal Zone Lymphoma. NCI Thesaurus. Code C8863.

A primary nodal B-cell non-Hodg kin lymphoma which morphologically resembles lymph nodes involved by marg inal zone lymphomas of extranodal or splenic types, but without evidence of extranodal or splenic disease. (WHO, 2001) 